\title{
SIGNIFICANDO O ENSINO DE QUÍMICA ATRAVÉS DO CONGRESSO DESENVOLVENDO O CARÁTER QUÍMICO - CONDECQ
}

\author{
Jéssica Vanessa Diniz da Silva ${ }^{1}$; Eliemerson de Souza Sales ${ }^{2}$ \\ ${ }^{1}$ Universidade Federal de Pernambuco, jvdinizsilva@gmail.com \\ ${ }^{2}$ Universidade Federal de Pernambuco, eliemersonsales@gmail.com
}

\section{RESUMO}

O presente trabalho refere-se a uma pesquisa qualitativa sobre uma proposta de desenvolver congressos na escola básica, fundamentados nas Metodologias de Ativas de Aprendizagem - MAA, com o objetivo de significar o Ensino de Química. Os participantes da pesquisa foram alunos 105 estudantes dos $6^{\circ}, 9^{\circ}$ anos do ensino fundamental e $2^{\circ}$ e $3^{\circ}$ anos do ensino médio de uma escola privada no município de Nossa Senhora do Ó - Ipojuca, Pernambuco. Os corpus empírico dessa pesquisa foram avaliações diagnósticas e prognósticas, além de depoimentos dos alunos que avaliaram a realização do evento. Os resultados mostraram que os estudantes aprovaram a realização do congresso como facilitadora aprendizagem.

\section{INTRODUÇÃO}

Diante do constante processo de mudança e ruptura da humanidade a educação assume um papel muito importante para a formação social. Em contraposição, mesmo diante de tantas mudanças, muitos professores ainda mantém as metodologias que se amparam no modelo de transmissão-recepção, pautadas na racionalidade técnicas, ficando em evidencia os processos de memorização e reprodução de informações, sendo estas concebidas como sendo conhecimentos adquiridos.

O papel do Ensino de Química atualmente está relacionado não apenas a compreensão de fenômenos da natureza, mas a tomada de decisões que são oriundas da apropriação dos conhecimentos científicos. Nesse contexto, ainda é um consenso entre professores e pesquisadores que se dedicam aos temas relacionados ao Ensino de Ciências, que o Ensino de Química pouco tem despertado o interesse dos estudantes para essa área do conhecimento, sobre isso Pozo e Crespo (2009) discorrem coerentemente.

A produção de conhecimento acerca de metodologias ativas, alternativas, de baixo custo, dentre outras, tem sido caminhos propostos para que os conhecimentos científicos façam parte do processo formativo de forma que os estudantes se apropriem destes conhecimentos e confiram significados a estes, relacionando-os aos seu contexto histórico-social, fazendo desta forma sentido para eles a apropriação de tais conhecimento. Nessa direção, a educação científica se torna o coração do Ensino de Ciências, na intenção de que os estudantes desenvolvam uma perspectiva de ciência e 
tecnologia que considere a história das ideias científicas, sua natureza e a sua real importância na vida pessoal e social dos mesmos (GIL-PÉREZ; VILCHES, 2005).

\section{FUNDAMENTAÇÃO TEÓRICA}

Muito ainda tem sido discutido sobre o papel da escola e quais suas contribuições para a formação integrada e efetiva dos indivíduos na sociedade. Em decorrência das mudanças na sociedade em decorrência do desenvolvimento da ciência e da tecnologia, a legislação nacional também foi acompanhada de mudanças que prevê objetivos préestabelecidos no qual os níveis de ensino devem se propor a alcançar, a saber:

Do ensino fundamental - A compreensão do ambiente natural e social, do sistema político, da tecnologia, das artes e dos valores em que se fundamenta a sociedade; O desenvolvimento da capacidade de aprendizagem, tendo em vista a aquisição de conhecimentos e habilidades e a formação de atitudes e valores (LEGISLAÇÃO, art. 32, II e III);

Do ensino médio - A preparação básica para o trabalho e a cidadania do educando, para continuar aprendendo, de modo a ser capaz de se adaptar com flexibilidade a novas condições de ocupação ou aperfeiçoamento posteriores; $\mathrm{O}$ aprimoramento do educando como pessoa humana, incluindo a formação ética e o desenvolvimento da autonomia intelectual e do pensamento crítico; A compreensão dos fundamentos científico-tecnológicos dos processos produtivos, relacionando a teoria com a prática, no ensino de cada disciplina (LEGISLAÇÃO, art. 35, II, III e IV).

Assim, observa-se como supracitado que, a escola tem o papel de ser promotora da autonomia e do pensamento crítico, além de ser formadora de atitudes e valores. Ou seja, a escola deve alfabetizar os estudantes cientificamente no que concerne as disciplinas que se relacionam com os conhecimentos de ciências. Isso significa preparar os estudantes não apenas para entender o mudo que o cercam, mas também de transformálo (CHASSOT, 2010) e isso consiste em um dos maiores desafios em ensinar Ciências.

Segundo Berbel (2011), o despertar do interesse do aluno é um fator fundamental para que ele venha exercer a autonomia e a tomada de decisões. O professor é o maior responsável por despertar a curiosidade e criar situações onde o aluno possa se posicionar. Isso significa, por exemplo, em trazer discussões, debates, mostrar um conteúdo em várias visões (quando possível). A relação professor-aluno é dinâmica, na qual ambos aprendem juntos e a prática, orientada pela teoria, pode ser reorientada durante o processo.

As Metodologias Ativas de Aprendizagem (MAA), segundo Berbel (2011), são métodos que procuram desenvolver o processo de aprendizagem, utilizando de problemas 
reais ou simulados, com o intuito de solucionar os desafios apresentados em diferentes contextos.

As metodologias ativas tem o potencial de despertar a curiosidade, à medida que os alunos se inserem na teorização e trazem elementos novos, ainda não considerados nas aulas ou na própria perspectiva do professor. Quando acatadas e analisadas as contribuições dos alunos, valorizando-as, são estimulados os sentimentos de engajamento, percepção de competência e de pertencimento, além da persistência nos estudos, entre outras (BERBEL 2011, p. 28).

Ensinar através das MAA propicia não apenas autonomia como o pensamento crítico-reflexivo do aluno, mas também oportuniza aos docentes apresentar conhecimentos que muitas vezes não são vivenciados na sala de aula. Além disso, quando o aluno é estimulado a despertar sua curiosidade, automaticamente ele começa a interagir, a discutir, ele começa a contribuir no processo de ensino-aprendizagem trazendo ideias ou até mesmo temáticas ou problemas que lhe instiga.

Para isso, propõe o desenvolvimento de congressos na escola básica, fundamenta nas MAA com foco no ensino de Química como uma maneira inovadora para a construção dos conhecimentos científicos mais significativos.

\section{METODOLOGIA}

Antes de tudo, é importante destacar que essa pesquisa se filia aos pressupostos da pesquisa qualitativa sendo as discussões construídas com base nesse paradigma de pesquisa.

\section{O campo de Pesquisa}

Esta pesquisa foi desenvolvida na escola José Benjamin de Souza Leão da rede privada de ensino localizada no município de Nossa Senhora do Ó - Ipojuca, Pernambuco.

\section{Os participantes da Pesquisa}

Participaram desse estudo estudantes do $6^{\circ}$ e $9^{\circ}$ ano do Ensino Fundamental, além de estudantes do $2^{\circ}$ e $3^{\circ}$ ano do Ensino Médio. Ao todo, foram 105 estudantes. 


\section{Os instrumentos de Coleta de dados}

Se configurou enquanto instrumento de coleta de dados os questionários diagnósticos e prognósticos que foram realizados antes e após a vivência das atividades propostas, além de depoimentos dos estudantes que avaliaram a realização do CONDECQ..

\section{Procedimentos da Pesquisa}

As atividades foram desenvolvidas individualmente em cada turma durante o decorrer das aulas. Portanto, cada turma desenvolveu uma atividade diferente de acordo com o conteúdo curricular que estava sendo previsto. A tabela abaixo nos ajuda a sistematizar a relação dos conteúdos trabalhados em casa turma com as atividades desenvolvidas:

\begin{tabular}{cccc}
\hline \multicolumn{3}{c}{ Tabela 1. Relação conteúdo da unidade com as atividades desenvolvidas no } \\
CONDECQ por turma
\end{tabular}

Inicialmente, fez-se necessário levantar os conhecimentos prévios dos estudantes acerca da temática que iriam estudar. Para tanto, fez-se necessário aplicar um questionário diagnósticos com quatro questões. A título de exemplo, abaixo apresentamos as perguntas do questionário diagnóstico destinado aos estudantes do $6^{\circ}$ ano do Ensino Fundamental que se dedicaram a aprendizagens do conteúdo "solos":

1. O que é $\mathrm{pH}$ ?

2. O pH 5 é considerado ácido, neutro ou básico (alcalino)?

3. Qual é a importância de estudar o pH do solo?

4. Qual é a importância da realização do experimento? 
Dando sequência, abaixo buscamos descrever como as atividades foram desenvolvidas:

- Para $6^{\circ}$ anos:

A proposta foi desenvolvida no $6^{\circ}$ ano do Ensino Fundamental II, com um total de 28 estudantes na turma A e de 23 estudantes na turma B. Como o assunto da unidade vigente era solo, a atividade desenvolvida consistia em determinar, por comparação, o pH de várias amostras (leite, sabão, vinagre) com o pH de três solos: solo 1 - com matéria orgânica, solo 2 - com cal virgem, solo 3 - solo, apenas. Através desse problema, construtos teóricos como conceito de $\mathrm{pH}$ e a importância do conhecimento de $\mathrm{pH}$ do solo foram construídos. Em cada turma, foram formados dois grupos.

- Para $9^{\circ}$ anos:

A proposta desenvolvida nos $9^{\circ}$ anos do Ensino Fundamental II, com um total de 23 estudantes na turma A e de 10 na turma B. Como o assunto da unidade vigente era separação de misturas, a atividade consistia em desenvolver uma Estação de Tratamento de Água - ETA e explicar seu funcionamento; transformar água bruta em água "potável”; mostrar os processos de separação de misturas numa ETA; levar amostras para fazer a separação de misturas na ETA, para a turma A. Já na turma B, a atividade consistia em desenvolver um destilador simples; levar amostras para fazer separação no destilador; explicar o processo de destilação e onde esse processo é utilizado.

- $\quad$ Para $2^{\circ}$ e $3^{\circ}$ anos:

A proposta desenvolvida no Ensino Médio com um total de 21 estudantes. Como o assunto da unidade vigente era Estequiometria (para o $2^{\circ}$ ano) e Química Orgânica (para o $3^{\circ}$ ano), a atividade consistia em desenvolver um enredo com princípios éticos sobre Química criminal para criação de curta-metragem; Identificar a causa da morte através da detecção de digitais; Relacionar os conteúdos de Química Orgânica e Estequiometria com a temática; Utilizar experimento na curta-metragem envolvendo os conteúdos químicos; Apresentar o experimento após exibição do curta-metragem, com devida explicação sobre os conteúdos químicos envolvidos no experimento contido no curta. Os alunos das duas turmas foram mesclados e sorteados para formarem dois grupos. Não contamos com estudantes dos $1^{\circ}$ anos, pois a escola não havia formado turmas dessa série. 
Os experimentos foram realizados pelos estudantes em suas residências sob a supervisão de um adulto tendo como requisito a observação e registro dos procedimentos através do uso da ferramenta Mobile Learning como facilitadora na aprendizagem.

Em todas as turmas, tiveram-se três aulas semanais, nas quais duas foram reservadas para os conteúdos de química ou ciências (no caso, dos $6^{\circ}$ e $9^{\circ}$ anos) e uma para as atividades desenvolvidas pelos alunos para acompanhamento e regulação do professor.

$\mathrm{Na}$ intenção de avaliar os conhecimentos construídos pelos estudantes a partir das atividades propostas, foi aplicado um questionário prognóstico que além das perguntas iniciais, continha perguntas referentes as atividades desenvolvidas. $\mathrm{O}$ mesmo foi aplicado após o dia do congresso CONDECQ. Abaixo a título de exemplo apresentamos as perguntas do questionário prognóstico aplicado aos estudantes o $6^{\circ}$ ano:

1. O que é pH?

2. O pH 5 é considerado ácido, neutro ou básico (alcalino)?

3. Qual é a importância de estudar o pH do solo?

4. Qual é a importância da realização do experimento? Foi melhor aprender dessa forma?

5. Como a equipe determinou o $\mathrm{pH}$ das 3 amostras de solo?

a) Comparando, através de cor, com o pH das 9 substâncias que tinham $\mathrm{pH}$ conhecido

b) Comparando, através de cor, com o pH das 9 substâncias que tinham $\mathrm{pH}$ desconhecido

c) Pesquisando na internet

A unidade foi focada no desenvolvimento dessa atividade, ou seja, foram 8 semanas de realização das atividades, culminando na realização do Congresso Desenvolvendo o Caráter Químico - CONDECQ. A programação do CONDECQ foi planejada da seguinte maneira:

- Apresentação das atividades desenvolvidas

- Exibição do CSI

- Minicursos

$\mathrm{Na}$ realização de minicursos com temáticas escolhidas pelos próprios alunos, foram elas: fabricação de perfume e fabricação de hidratantes. Esses minicursos foram 
ministrados por graduandos de licenciatura em química da Universidade Federal de Pernambuco, os mesmos receberam certificados. Todos os alunos da escola que não foram participantes da pesquisa, ou seja, não desenvolveram as atividades, foram os ouvintes dos trabalhos e também participaram dos minicursos. Foi lançado na escola um período de inscrição para eles uma semana anterior a semana do congresso.

Os demais professores da escola e os graduandos de licenciatura em química que ministraram os minicursos (ambos chamados de comissão avaliadora) avaliaram os trabalhos dos alunos. Eles receberam uma ficha que continham os objetivos de cada atividade e os requisitos que eles deveriam avaliar conforme tópicos abaixo (a título de exemplo para as turmas dos $6^{\circ}$ anos):

- O objetivo do trabalho foi (conhecer o conceito de $\mathrm{pH}$; Observar $\mathrm{pH}$ ácidos, básicos e neutros de diferentes substâncias); Determinar o pH das amostras de solo a partir das cores das diferentes substâncias; Discutir a importância do conhecimento do $\mathrm{pH}$ do solo e como o $\mathrm{pH}$ interfere na coloração das plantas).

- A equipe demonstrou conhecimento sobre o conceito de $\mathrm{pH}$ ?

- A equipe observou os $\mathrm{pH}$ de todas as substâncias que foram solicitadas?

- A equipe determinou o pH das amostras de solo a partir das cores das diferentes substâncias?

- A equipe discutiu a importância de $\mathrm{pH}$ do solo e como o pH interferiu na coloração de certas plantas?

$\mathrm{Na}$ ficha também continha uma tabela ao final, na qual a comissão avaliadora marcava a nota quanto organização da equipe, domínio do assunto, entusiasmo e motivação e banner ou cartazes com foto.

\section{RESULTADOS E DISCUSSÕES}

Os dados coletados com os $6^{\circ}$ anos revelaram que na avaliação diagnóstica com relação a questão $1,0 \%$ dos estudantes souberam conceituar o que é pH e, com relação a questão 2, 60\% dos estudantes definiram que 5 é um pH ácido. Já na avaliação prognóstica com relação a questão 1, $80 \%$ dos alunos conseguiram definir o que é pH e, com relação a questão 2, 77\% conseguiram saber que 5 é um pH ácido. Esses resultados indicam que os alunos conseguiram, através do experimento, definir um conceito de $\mathrm{pH}$, sendo muito 
mais fácil construir esse conceito através da prática do que simplesmente ele ser transpassado para o quadro. Além disso, os alunos pesquisaram e consultaram o professor sobre a escala de $\mathrm{pH}$ e qual sua utilidade. Com isso, percebeu-se que $77 \%$ dos alunos conseguiram responder que 5 é considerado um pH ácido.

Com relação a questão 4 na avaliação diagnóstica, apenas $10 \%$ dos alunos argumentaram que a importância de estudar pH do solo era para saber a composição química do solo ou para saber se o solo era fértil ou não. Essa mesma questão na avaliação prognóstica obteve $91 \%$ de respostas. As visões mais interessantes estão descritas abaixo:

"Para descobrir se o solo é ácido, básico ou alcalino. Sim, porque é uma forma diferente de se estudar e todos aprenderam mais” Aluno A

"Para nós aprendemos mais sobre química, foi melhor, pois expormos fora de um papel o que aprendemos” Aluno B

"A importância foi de medir o pH do solo, foi melhor aprender desse jeito porque foi mais demonstrativo e a aprendizagem dessa forma foi mais divertida" Aluno C

"O trabalho foi importante para aprender o que é pH e outras coisas que eu não sabia. Sim, foi melhor aprender dessa forma porque a gente discutiu e corrigiu o que tava errado" Aluno D

Os depoimentos desses alunos foram unânimes no que se refere sobre como o conhecimento se torna mais significativo através da prática, as imagens 1, 2 e 3 abaixo retratam os experimentos realizados por eles. Esses depoimentos também direcionam como está se dando o processo de ensino-aprendizagem e orienta o professor sobre sua prática docente.

Um dos pontos que merecem ser destacados é que os $6^{\circ}$ anos tem aulas de ciências com alguns conteúdos que apresentam iniciação à química. Essa experiência fez com que os alunos se aproximassem ainda mais da disciplina. Esse foi um dos fatores fundamentais para nomearmos o nome do evento como CONDECQ, pois a ideia é justamente do aluno desenvolver o lado experimental, científico em química.

Imagem 1: Alunos dos $6^{\circ}$ anos apresentando os resultados 


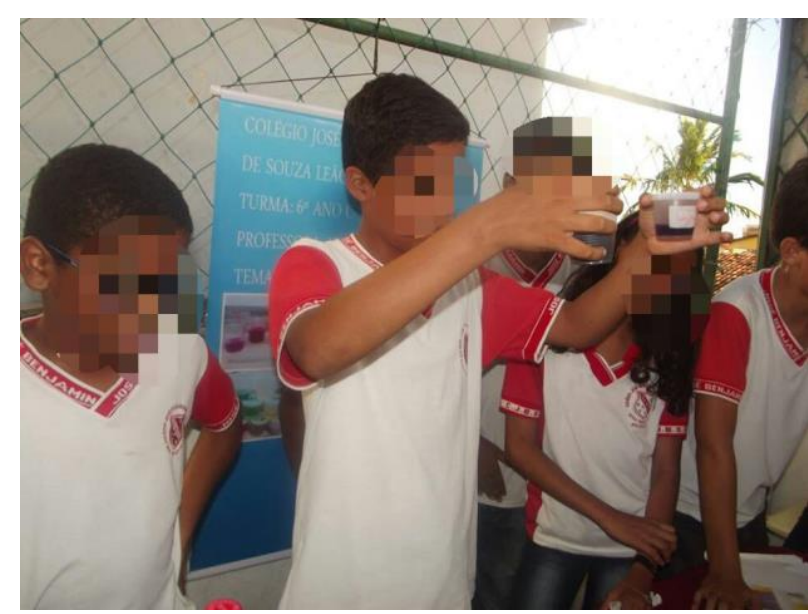

Imagem 2: Graduanda em licenciatura em Química (da comissão avaliadora) avaliando a atividade do $6^{\circ}$ ano

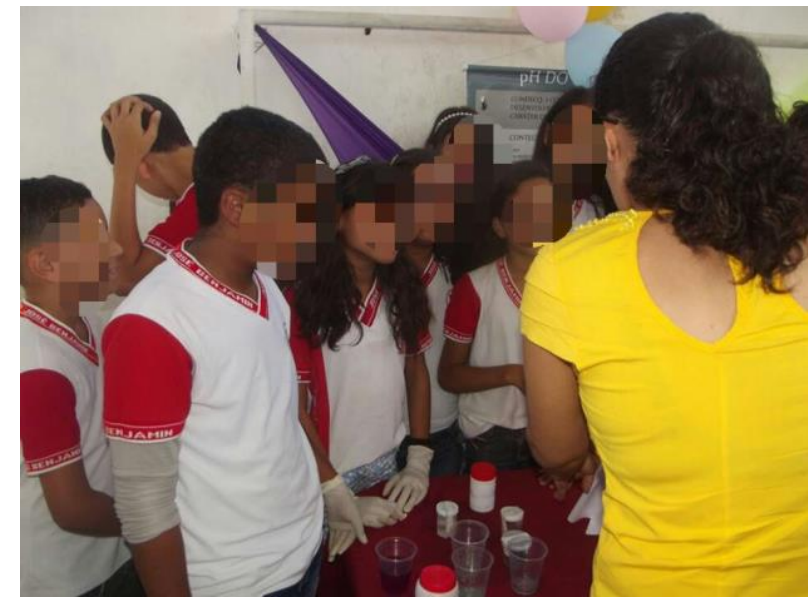

Imagem 3: Uma das equipes dos $6^{\circ}$ anos com o trabalho de $\mathrm{pH}$ do solo

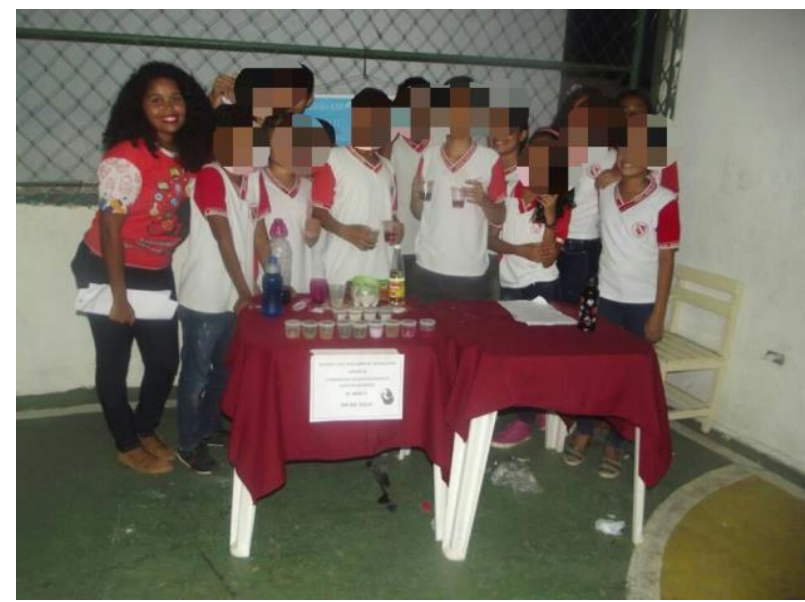

Ressaltamos que foi realizado um recorte dos dados obtidos devido ao espaço para discussão neste trabalho. No entanto, acreditamos que os dados apresentados nos ajudam a compreender o quanto efetivo foram as atividades realizadas. 
Os dados coletados com os $9^{\circ}$ anos A e B, com relação sobre a importância da realização dessa atividade, selecionamos os argumentos dos alunos nas avaliações diagnósticas e prognósticas, respectivamente e elencamos abaixo:

Tabela 2. Comparação dos argumentos dos alunos nas avaliações diagnósticas e prognósticas

\begin{tabular}{|c|c|c|c|}
\hline Aluno & Turma & $\begin{array}{l}\text { Qual foi a importância de } \\
\text { realizar o experimento? } \\
\text { (Avaliação diagnóstica) }\end{array}$ & $\begin{array}{l}\text { Qual foi a importância de } \\
\text { realizar o experimento? } \\
\text { (Avaliação prognóstica) }\end{array}$ \\
\hline $\mathrm{E}$ & $\begin{array}{l}9^{\circ} \text { ano } \\
\mathrm{A}\end{array}$ & $\begin{array}{l}\text { "É importante } \\
\text { aprendermos o para } \\
\text { melhor". }\end{array}$ & $\begin{array}{l}\text { "Foi bom, porque através } \\
\text { da experiência a gente } \\
\text { apendeu como se faz para } \\
\text { que a água chega em nossa } \\
\text { casa". }\end{array}$ \\
\hline$F$ & $\begin{array}{c}9^{\circ} \text { ano } \\
\mathrm{A}\end{array}$ & $\begin{array}{l}\text { "Para entendermos melhor } \\
\text { como funciona o processo de } \\
\text { separação de misturas, seja } \\
\text { ela homogênea } \\
\text { heterogênea". }\end{array}$ & $\begin{array}{l}\text { "Conhecer melhor como } \\
\text { funciona. Sim, porque na } \\
\text { prática se dá melhor a } \\
\text { entender do que na teoria". }\end{array}$ \\
\hline G & $\begin{array}{l}9^{\circ} \text { ano } \\
\text { B }\end{array}$ & $\begin{array}{l}\text { "Para que possamos entender } \\
\text { melhor". }\end{array}$ & $\begin{array}{l}\text { "Para entender melhor } \\
\text { como acontecem os } \\
\text { processos de separação de } \\
\text { misturas. Sim, pois } \\
\text { praticando é mais fácil de } \\
\text { entender". }\end{array}$ \\
\hline $\mathrm{H}$ & $\begin{array}{l}9^{\circ} \text { ano } \\
\text { B }\end{array}$ & $\begin{array}{l}\text { "Para que a gente entenda } \\
\text { melhor o assunto". }\end{array}$ & $\begin{array}{l}\text { "Foi muito importante, uma } \\
\text { forma legal de aprender e } \\
\text { simples, pois com o } \\
\text { experimento foi mais fácil } \\
\text { de compreender a } \\
\text { separação de mistura". }\end{array}$ \\
\hline
\end{tabular}

Os depoimentos desses alunos indicaram como o desenvolvimento da atividade contribuiu para compreensão do conteúdo teórico vivenciado na sala, dando a oportunidade de os alunos usarem sua criatividade para montar seja a ETA, seja o destilador simples. Além disso, os alunos apresentaram uma melhor argumentação e postura na apresentação dos trabalhos.

Os dados coletados com os $2^{\circ}$ e $3^{\circ}$ anos, com relação a como as equipes conseguiram relacionar os conteúdos de química a criação do curta-metragem, a 
importância da realização dessa atividade e as dificuldades encontradas, selecionamos os argumentos dos alunos nas avaliações prognósticas e dispomos na tabela abaixo:

\begin{tabular}{|c|c|c|c|c|}
\hline Aluno & Turma & $\begin{array}{l}\text { Como a equipe } \\
\text { conseguiu relacionar a } \\
\text { construção do CSI com } \\
\text { os conteúdos de } \\
\text { Química? }\end{array}$ & $\begin{array}{l}\text { Qual foi a importância de } \\
\text { realizar o experimento? }\end{array}$ & $\begin{array}{l}\text { Dificuldades } \\
\text { encontradas }\end{array}$ \\
\hline I & $3^{\circ}$ ano & $\begin{array}{l}\text { Na busca pelos } \\
\text { experimentos, podemos } \\
\text { descobrir maneiras } \\
\text { diferentes para fazer o } \\
\text { mesmo, então foi } \\
\text { interessante para tentar } \\
\text { em casa, depois. }\end{array}$ & $\begin{array}{l}\text { Foi importante por } \\
\text { descobrir coisas novas, } \\
\text { usando a química no dia a } \\
\text { dia. }\end{array}$ & $\begin{array}{l}\text { Não houveram } \\
\text { dificuldades }\end{array}$ \\
\hline $\mathrm{J}$ & $3^{\circ}$ ano & $\begin{array}{l}\text { Utilizando o experimento } \\
\text { que continha o assunto } \\
\text { estudado em sala de } \\
\text { química orgânica. }\end{array}$ & $\begin{array}{l}\text { Para mostrar que a química } \\
\text { orgânica está envolvida em } \\
\text { consideravelmente tudo na } \\
\text { nossa vida; e foi uma forma } \\
\text { interessante e diferente de } \\
\text { aprender. }\end{array}$ & $\begin{array}{l}\text { Falta de diálogo, } \\
\text { convívio e apoio } \\
\text { da coordenação } \\
\text { escolar. }\end{array}$ \\
\hline $\mathrm{L}$ & $2^{\circ}$ ano & $\begin{array}{l}\text { Foi preciso identificar } \\
\text { uma molécula (amido) } \\
\text { para achar a quantidade } \\
\text { de carbono. Esse } \\
\text { processo só se deu por } \\
\text { meio do experimento, } \\
\text { feito para simular o pó } \\
\text { usado por peritos. }\end{array}$ & $\begin{array}{l}\text { Foi importante para } \\
\text { identifcar que a função de } \\
\text { elementos simples também } \\
\text { são capazes de substituir } \\
\text { elementos mais complexos. } \\
\text { Essa foi a melhor forma de } \\
\text { aprender e fixar o assunto, já } \\
\text { que foi levado a parte } \\
\text { prática. }\end{array}$ & $\begin{array}{l}\text { Houveram } \\
\text { dificuldades } \\
\text { com as } \\
\text { gravações e com } \\
\text { a estrutura do } \\
\text { curta. }\end{array}$ \\
\hline
\end{tabular}

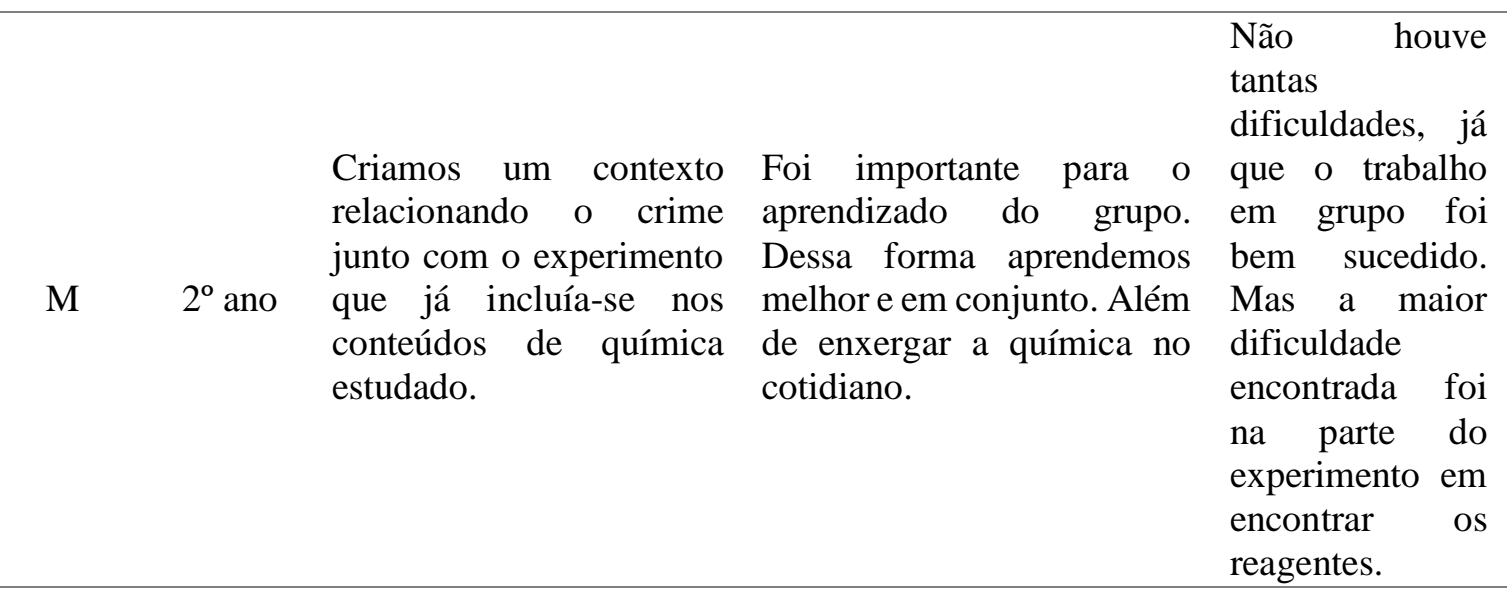

Os depoimentos dos alunos evidenciaram que os mesmos acharam muito interessante a proposta de construção do conhecimento através da criação e produção do curta. Acharam trabalhosa a ideia de criar um enredo, roteiro e a relação com o conteúdo 
de química. Eles perceberam que a química está presente nas coisas simples do cotidiano. A fala do aluno L chamou-nos a atenção, pois o mesmo percebeu a importância de ter realizado o experimento com materiais de baixo custo. Essa mesma equipe havia se preocupado em comprar reagentes mais sofisticados para realização do experimento. Depois de dialogar com o professor, eles perceberam que haviam outras possibilidades para realiza-los. Nas dificuldades encontradas, os alunos $\mathrm{J}$ e $\mathrm{L}$ estavam na equipe que encontraram maiores dificuldades de convívio com os colegas com relação ao enredo do curto, o que fez os alunos não se motivassem para concluir o trabalho.

\section{CONCLUSÃO}

Diante do exposto, pode-se observar que a utilização das atividades que constituíram o Congresso Desenvolvendo o Caráter Químico - CONDECQ se mostraram como uma possibilidade para significar o Ensino de Química. O CONDECQ foi um momento que oportunizou os alunos para argumentar e enxergar que os conteúdos vivenciados podem transpor o espaço da sala de aula. Ressaltamos que os alunos, em geral, aprovaram a proposta de poderem construir o conhecimento através da prática para, em seguida, associarem ao conteúdo vivenciado na sala.

A produção de conhecimento através das MAA mostrou-se como um caminho para que os conhecimentos científicos se tornassem mais significativo para a formação integrada e efetiva dos estudantes.

\section{REFERÊNCIAS}

BERBEL, N.A.N. As metodologias ativas e a promoção da autonomia de estudantes. Semina: Ciências Sociais e Humanas, Londrina, v. 32, n. 1, p. 1- 16, 2011.

CACHAPUZ, A., GIL-PEREZ, D., PESSOA DE CARVALHO, A. M., PRAIA, J., VILCHES, A. A necessária renovação no ensino de ciências. São Paulo: Editora Cortez, 2005.

CHASSOT, A. Alfabetização Científica: questões e desafios para a educação. Rio Grande do Sul: Editora Unijuí, 2000.

POZO, J. I.; CRESPO, M. A. G. A aprendizagem e o ensino de ciências: do conhecimento cotidiano ao conhecimento científico. 5. ed. Porto Alegre: Artmed, 2009.

http://portal.mec.gov.br/seesp/arquivos/pdf/lei9394_ldbn1.pdf, acesso em 29.09.2017 